\title{
RISCOS, VULNERABILIDADES E RESILIENCIA SOCIOAMBIENTAIS URBANAS: INOVAÇÕES NA ANALISE GEOGRÁFICA
}

\section{Urban Socio-Environmental Risks, Vulnerability and Resilience: Chalenges in Geographical Analysis}

Prof. Dr. Francisco Mendonça

Universidade Federal do Paraná Centro Politecnico, Jardim das Américas, CEP: 81531-990 - Curitiba, PR - Brasil Tel/Fax: (+55 41) 33613458 / 33613450 - chico@ufpr.br

\section{$a a \boldsymbol{a}_{a a}$}

\begin{abstract}
Resumo
O inicio do século XXI encontra-se marcado pela concentração humana nas cidades. As áreas urbanas demandam, cada vez mais, atenção de cientistas e gestores urbanos, particularmente quando se trata da formação de riscos e vulnerabilidades socioambientais. A abordagem da resiliência no escopo da geográfica constitui algo de bem recente, todavia, ela demanda maior atenção dos geógrafos ao trabalharem com a realidade dos países do Sul: Em que condições se deveria buscar a resiliência nestes espaços? Estas três concepções trazem matrizes inovadoras na abordagem espacial ao requerem a analise da gênese dos problemas estudados como forma de compreender os processos atuais, bem como envolve diretamente a abordagem futura dos espaços (cenários). Desta maneira a geografia, no processo de planejamento urbano e regional, se vê impelida à uma abordagem que toma o espaço em sua acelerada dinâmica, rompendo com a perspectiva anterior no qual era tomado de forma estática. Os problemas do clima urbano, sob o enfoque da geografia, são tomados como exemplos ao longo do texto.
\end{abstract}

Palavras-chave: Riscos, vulnerabilidades, resiliencia, socioambiente, cidade.

\begin{abstract}
The beginning of the XXI century is marked by concentation of human population in the cities. Urban areas demand, more and more attention by scientists and urban managers, particularly when it comes to the formation of social and environmental risks and vulnerabilities. The approach of resilience in the geographical scope is something very recent, however, it demands greater attention from geographers to work with the reality of the South: Under what conditions should seek the resilience in these spaces? These three matrices (risk, vulnerabilitie and resilience) bring innovative concepts in the spatial approach, and requires analysis of the urban genesis problems in order to understand current processes and approach them concerning the future of space (scenarios). Thus geography in the process of urban and regional planning is compelled to take an approach that space in its accelerated dynamic, breaking the previous approach which was taken in a static way. The problems of urban climate, from the standpoint of geography, are taken as examples throughout the text.
\end{abstract}

Keywords: Risks, vulnerabilities, resilience, socioenvironment, cities.

\begin{abstract}
Résumé
.Le début du XXIème siècle est marqué par la population élevée dans les villes. Celles-ci demandent une attention de plus en plus grande par des scientifiques et des gestionaires urbaines, en particulier quand il s'agit de la formation de risques sociaux et envrionennementaux et les vulnérabilités. L'approche de la résilience dans le champ géographique est très récente, cependant, il exige une plus grande attention de la part des géographes qui étudient la réalité des pays du Sud : Dans quelles conditions se realise la résilience dans ces pays ? Ces trois matrices apportent des concepts inovants dans l'approche spatiale et nécessitent une analyse de la genèse des problèmes étudiés afin de comprendre les processus actuels qui impliquent directement l'avenir de l'espace (les scénarios). Ainsi la géographie, dans la planification et la gestion urbaine et régionale, est contraint de prendre une approche qui la place dans une dynamique spatiale plus accélérée, brisant l'approche précédente qui a été marqué par la perspective statique. Les problèmes du climat urbain sont ici pris comme d'exemples d'études.
\end{abstract}

Mots-clefs : Risques, vulnérabilités, résilience, socioenvironnement, villes. 


\section{INTRODUÇÃO}

Não obstante o conhecimento da sociedade acerca das trocas de influencias entre o clima e as atividades humanas, esta relação toma novos matizes no momento histórico presente. Muitos elementos entram em jogo na tessitura dos diferentes arranjos sócio-espaciais e socioambientais do espaço geográfico atual, cabendo à ciência e à técnica um papel destacado na investigação dos processos que resultam no mosaico e palimpsético objeto de estudo da geografia.

Marcados pelos processos associados de globalização e de mudanças globais, o espaço geográfico, as paisagens e territórios de interesse da geografia do presente inserem inúmeros desafios à sua compreensão. Ainda que a clássica abordagem dual da relação entre a natureza e a sociedade esteja na base deste campo do conhecimento, outras ainda se fazem bastante presentes, como é o caso dos estudos da relação cidade-campo, outrora de grande interesse à perspectiva geográfica. Este tema suscita, no presente, novas abordagens e reflexões, mesmo que alguns considerem que haja uma supremacia da lógica e dinâmica urbana em face da rural. Buscando avançar nas questões relativas a este debate, e mesmo reconhecendo-o como necessário, o texto a seguir evidencia uma preocupação com os espaços constituídos pelas cidades e alguns de seus problemas derivados.

Consta das estatísticas demográficas mais recentes a confirmação de que a maior parte dos homens vive hoje nos espaços urbanos, o que teria produzido também a compreensão de ser o século XXI "o século da cidade", enquanto o XX teria sido o da urbanização. Nesta nova condição, a de civilização-humanidade urbana, e portanto de alta densidade e concentração de pessoas no espaço, intensificam-se fluxos de toda ordem e a hibridização da natureza atinge suas potencialidades máximas. A cidade adquire, assim, o patamar ou nódulo central dos processos gerais derivados da sociedade humana sobre o espaço terrestre.

Mas a urbanização, enquanto processo de dinamização das cidades, não apresentaria nenhum problema em si mesma não fossem suas diferentes e complexas formas de manifestação. Considerando-se a tendência de formação de macro-regiões urbanas, ou cidades-região, nos países não desenvolvidos nas próximas décadas como seqüência à geografia das cidades na atualidade, muitos problemas se avizinham às preocupações humanas com a gestão urbana. A formação e agravamento de riscos de toda ordem, associados às vulnerabilidades da população, por exemplo, são aspectos que demandam um maior envolvimento da ciência, da técnica e da política no seu tratamento.

Compondo uma parte fundamental do estudo da cidade o clima, em particular o clima urbano, aparece como um recorte fundamental à compreensão dos problemas urbanos e à sua gestão no presente e no futuro. As situações de risco e de vulnerabilidades socioambientais urbanas relacionadas ao clima das cidades compõem o enfoque central deste texto.

\section{RISCO E VULNERABILIDADE SOCIOAMBIENTAL URBANA COMO UM PARADIGMA $\dot{A}$ CIÊNCIA}

Ao serem analisadas na perspectiva da qualidade e das condições de vida humanas as cidades apresentam consideráveis desafios aos geógrafos, isto para não falar da miriade de outros profissionais e dos gestores públicos e privados do espaço urbano. Outrora centrados em diagnósticos socio-espaciais e socio-ambientais os estudos atinentes às manchas urbanas pouco influenciaram para o desenvolvimento de perspectivas que tomassem a cidade como um todo; de maneira geral as produções acadêmicas alicerçaram planos diretores e intervenções parciais, especialmente nos países não desenvolvidos, comprovando em milhares de exemplos a concepção miltoniana de «urbanização corporativa» (Santos, 1993). O predominio do interesse economico e político na condução dos desenvolvimento urbano e regional caracteriza a história das cidades destes países na modernidade ocidental, o que conduz ao necessário abandono da acrítica expressão «urbanização expontanea».

Elemento constituinte e inerente do ambiente urbano o clima foi pouco considerado na elaboração do planejamento urbano das cidades ocidentais (MONTEIRO; MENDONÇA, 2003). Esta 
lacuna, dentre outras, garantiu à gestão das cidades uma supremacia de intervenções técnicas e parciais, conduzindo ao futuro da cidade a uma condição de palco de problemas de toda ordem. Embora tenha havido toda uma geração de urbanistas envolvidos e promotores da política de planejamento urbano, aspecto que marcou o desenvolvimento brasileiro de cidades de grande porte entre os anos 1960-1980, ela não evidenciou grandes realizações, pois a intensificação dos problemas socioambientais de toda ordem na atualidade testemunha as graves falhas de um processo parcial e excludente.

Para o sucesso dos planos diretores municipais e urbanos de então fazia-se mister a elaboração de diagnósticos detalhados das características geográficas e das potencialidades naturais e economicas dos municipios. Somente com base nestes é que se desenvolvia a segunda etapa do processo de planejamento urbano, que consistia na elaboração das diretrizes a serem tomadas para atingir o desenvolvimento urbano. A realidade do suporte físico-natural, das construções urbanas e da funcionalidade da cidade eram então conhecidas com base nos diagnósticos que, mesmo projetando uma «realidade futura» para a cidade, não avançava na especulação da alteração da paisagem ou na sua dinâmica (obstáculos epistemológicos - BACHELARD, 2006). A concepção predominante era aquela que encarava a realidade futura, material e imaterial, alvo do planejamento, como imutável ou estável no que concerne às características do momento no qual eram pensadas; ela refletia, de maneira clara, o pensamento de Kuhn (2006: 24), ao considerar que «a ciencia normal, atividade na qual a maioria dos cientistas emprega inevitavelmente quase todo seu tempo, é baseada no pressuposto de que a comunidade científica sabe como é o mundo», algo portanto previsível em exatidão.

Com a eclosão dos processos de globalização e de mudanças globais, no ambito dos quais especula-se acerca da rápida e intensa alteração das paisagens, as discussões acadêmicas e políticas passam a articularem-se em torno das incertezas dos cenários futuros para o planeta; ganha destaque a constituição de uma sociedade de risco (BECK, 1998) como regra geral do presente e do futuro próximo. Se a lógica do planejamento ambiental moderno embasava-se numa paisagem sem ou com muito pouca alteração - uma paisagem estável, a gestão urbana atual parece inserir, como paradigma dominante, a incerteza e a exacerbação das condições de riscos iminentes à sociedade futura - paisagem instável. Nesta condição observa-se algo de novo na abordagem da cidade, algo que se aproxima do que Kuhn (2006: 147) considera de revoluções científicas ao afirmar que «... durante as revoluções, os cientistas vêem coisas novas e diferentes quando, empregando instrumentos familiares, olham para os mesmos pontos já examinados anteriormente. É como se a comunidade profissional tivesse sido subitamente transportada para um novo planeta, onde objetos familiares são vistos sob uma luz diferente e a eles se apregam objetos desconhecidos».

Neste contexto a abordagem dos riscos socioambientais urbanos pode ser concebida como um novo paradigma, na medida em muda o foco da compreensão da lógica de produção e reprodução socioespacial ; ou seja, ela atesta a inserção de uma nova base de analise na relação sociedade - natureza, pois salta de uma base de certeza e estabilidade para uma outra de incerteza e de instabilidade quanto à repercussão dos processos naturais e sociais do espaço geográfico.

Veyret (2007), assim como Dubois-Maury e Chaline (2002) dentre inúmeros outros estudiosos desta temática são concordantes em conceber o risco segundo tres dimensões distintas, porém muitas vezes complementares entre si, quais sejam os riscos naturais, os riscos tecnologicos e os riscos sociais. Perspectivas mais recentes introduziram um aspecto mais amplo à estas reflexões tomando-as do ponto de vista da associação entre riscos e vulnerabilidades socioambientais urbanas (MENDONÇA, 2004 e 2004a).

Mas, como podemos conceituar os riscos socioambientais urbanos? Há várias possibilidades, todavia adiantamos a seguir uma das quais temos nos servido em nossas reflexões, ou seja, aquela que relaciona os riscos socioambientais às ameaças e aos perigos. Nesta perspectiva os riscos socioambientais urbanos dizem respeito aos fenomenos imbricados de contingencias naturais e sociais que desestabilizam as condições de vida das sociedades urbanas; eles evidenciam elementos e fatores de ordem natural (ambiental) e social (cultural, politica, economica e tecnológica). 
Uma das principais dimensões dos riscos, e de interesse das sociedades, é sua expressão espacial, ou seja, os riscos são espacial e temporalmente datados, o que os torna um dos temas de maior interesse da geografia atual. Neste aspecto não se trata de aborda-los de um ponto de vista apenas natural ou social, ainda que se possa fazê-lo, mas de buscar evidenciar sua expressão geográfica tendo por base a imbricação direta dos diferentes elementos componentes do espaço geográfico. É esta condição que evidencia a concepção dos riscos socioambientais como problemática complexa pois, sem o envolvimento do interesse social nos riscos naturais, por exemplo, eles permanecem no campo da dimensão física e da materialidade do universo, cuja dinamica natural é marcada por alterações e mudanças que se processam tanto de maneira lenta quanto rápida ou catastrófica, na sua quase totalidade fora da percepção humana.

Tomada deste ponto de vista a idéia tão propalada de que os homens se dividiriam entre aqueles do «tempo lento» versus aqueles do «tempo veloz» (Serres, 1993) suscita reflexões mais profundas. Embasada na concepção de que no ambito da natureza os processos somente acontecem de maneira muito lenta e morosa esta idéia parece se contrapor frontalmente à perspectiva das repercussões dos «natural hazards» sobre a sociedade. Os tempos, social e natural, estão a exigir dos cientistas e intelectuais, particularmente com a complexidade das interações entre a sociedade e a natureza na hipermodernidade, novos matizes que conduzam a analises e compreensões mais performantes.

A noção de risco introduz uma nova perspectiva na abordagem e gestão dos territórios, sejam eles urbanos ou rurais, litoraneos ou continentais, naturais ou fortemente alterados. Ela constitui-se num novo paradigma - como anteriormente mencionado, com especial repercussão sobre a perspectiva do planejamento ao forjar a mudança da concepção predominante de estabilidade do espaço ou da natureza, uma vez que fundamenta-se na idéia de incerteza quanto às paisagens futuras, especialmente ao admitir os processos de mudanças globais e globalização em curso.

Diretamente associada aos riscos está a vulnerabilidade socioambiental urbana que, também atrelada a uma série de contingencias sociais, politicas, economicas, culturais, tecnologicas, etc. explicitam diferentes condições de exposição e de fragilidade de grupos sociais aos riscos. Dito de outra maneira, a vulnerabilidade socioambiental urbana evidencia a heterogeneidade dos impactos advindos dos riscos que se abatem sobre uma dada população, constituindo ambos - risco e vulnerabilidade socioambiental urbana - uma seara de alta complexidade para a compreensão e gestão urbana.

Entender e promover a gestão socioambiental urbana tornou-se um desafio premente em países como o Brasil, nos quais a densidade e magnitude da rede urbana e das cidades são marcadas por problemas de toda ordem, dentre os quais se sobressai a intensificação dos riscos e vulnerabilidades socioambientais. Concebida e administrada de forma cartesiana e socialmente injusta e excludente, a cidade brasileira está a exigir, de cientistas, técnicos e gestores novas bases teóricas e metodológicas que a tomem de modo mais abrangente. Neste sentido propusemos (Mendonça, 2004 e 2004a), no inicio desta década e em conformidade com a perspectiva interdisciplinar / diálogo de saberes, o SAU - Sistema Socioambiental Urbano, uma contribuição teórico-metodológica para o estudo e a gestão das cidades. A aplicação da mesma em várias situações tem revelado um rico e promissor campo de possibilidades para o exercício acadêmico, técnico e político da interação entre a sociedade e a natureza nos espaços urbanos visando o equacionamento e/ou soluções de problemas socioambientais urbanos.

Mais recentemente observamos que vários grupos de pesquisadores buscam a inserção da concepção de resiliencia como uma premissa inovadora na analise dos problemas socioambientais urbanos envolvendo riscos e vulnerabilidades. Trata-se de um conceito relacionado à adaptação e consiste em variações individuais e/ou em resposta aos fatores de risco, e refere-se, em geral, à capacidade de um ambiente, ou sociedade, de voltar às condições anteriores após ser impactada/ vitimada por um evento de caráter extremo (natural ou social/tecnológico hasard). Originária do 
âmbito das ciências naturais, e conhecendo algum desenvolvimento quando do emprego na psicologia, a resiliência nos apresenta enormes desafios e questionamentos quando pensada no contexto da urbanização corporativa dos países não desenvolvidos.

Em boa parte das vezes, nos contexto dos países “do Sul”, não se deve buscar recompor, em nenhuma hipótese, as condições pré-existentes dos lugares e nem das sociedades impactados por adversidades (riscos) naturais, sociais ou tecnológicas. Por que não? Porque as condições pré-existentes de grande parte das populações e cidades dos países não desenvolvidos já são extremamente excludentes, injustas e degradadas antes mesmo da ocorrência de qualquer evento adverso ou extremo - hazards. Muitas das situações pré-existentes constituem realidades compostas, em si mesmas, de total risco e vulnerabilidades diversas à eles, não sendo recomendado o retorno às mesmas. Uma tal proposição, da resiliência, parece encontrar boa aplicação no contexto dos países desenvolvidos, uma vez que ali a condição socioambiental contemporânea é, em geral, de boa qualidade e condições de vida para a maioria da população; nestes contextos a possibilidade ou busca de retorno ao estado anterior, parece uma boa alternativa.

Riscos, vulnerabilidades e resiliência constituem um tripé de fundamental importância para os estudos geográficos, não somente porque inovam as abordagens da produção deste campo do conhecimento, mas porque introduzem também uma nova perspectiva na percepção e analise dos espaços geográficos. De maneira geral este era tomada, na maioria dos estudos, como ao estático ou com alterações muito lentas, sobre o qual a prática do planejamento urbano e regional, por exemplo, projetava perspectivas sem grandes alterações do quadro natural sobre/com o qual a sociedade se organiza. Assim se observa que as perspectivas lançadas na maioria dos planos diretores tomavam o quadro o suporte natural como estático e a sociedade de forma dinâmica, particularmente dinamizada pelos processos socioeconômicos.

Estas três concepções acabam por inovar a perspectiva geográfica por vários motivos, dos quais vale destacar: a) a aceleração das mudanças tanto de ordem social quanto natural que se processam no espaço, ou seja, a aceleração da dinâmica das paisagens; b) a necessária abordagem escalar temporal, ou seja, coloca como imperativo o necessário conhecimento dos processos passados geradores da situação atual e, a inserção da perspectiva futura, ao trabalhar com cenários decorrentes de mudanças dos vários elementos da paisagem ; e, c) a consideração dos princípios da incerteza, da responsabilidade e da precaução na construção das condições futuras da vida no planeta. Tomadas sob esta perspectiva elas realçam tanto uma superação de importantes obstáculos epistemológicos (Bachelard, 2006) quanto de rupturas epistemológicas (Kuhn, 2006) no campo da geografia.

\section{O CLIMA URBANO SOB A PERSPECTIVA DO RISCO E DA VULNERABILIDADE SOCIOAMBIENTAL}

Subsistema do SAU - Sistema Ambiental Urbano, o SCU - Sistema Clima Urbano (MONTEIRO; MENDONÇA, 2003) consiste numa das primeiras propostas teórico-metodológicas produzidas no Brasil que apontam a necessidade do tratamento integrado dos elementos constituintes do ambiente das cidades na perspectiva do planejamento urbano. Já na década de 1960 seu proponente chamava a atenção da academia e da política para o necessário cuidado que deveria ser tomado quanto à urbanização do país, e a premência de sua abordagem de um ponto de vista amplo, teórico e aplicado.

Na proposição do SCU três são os campos de enfoque que devem ser desenvolvidos, quais sejam: a) o campo termodinâmico, b) o campo físico-químico e, c) o campo hidrometeórico. Os problemas socioambientais urbanos relativos aos mesmos são, em geral, os seguintes: a) desconforto térmico ou ambiental, ilhas de calor e ilhas de frescor; b) poluição atmosférica, inversão térmica e chuvas ácidas; e, c) inundações e movimentos de terra, respectivamente. Os problemas relacionados ao primeiro e ao último subsistema do clima urbano estão relacionados, em muitas das vezes, às 
próprias características dos climas tropicais quentes e úmidos, sendo intensificados em decorrência da urbanização-industrialização corporativa que se desenvolveu nas regiões tropicais; o segundo campo está diretamente ligado à este processo.

Embora caracterizado como um país tropical e, portanto, com excesso de energia devido às suas condições naturais, algumas das cidades localizadas na porção sul do país registra situações diárias e sazonais de muito baixas temperaturas (médias diárias e invernais inferiores a $5^{\circ} \mathrm{C}$ e $10^{\circ} \mathrm{C}$, respectivamente), o que decorre na formação de ilhas de frescor de forte intensidade. Aliado às condições de frio da atmosfera na escala do canopy layer (OKE, 1973) a infra-estrutura de habitação e de edificações de serviços públicos (escolas, hospitais, repartições, etc.) é fortemente permeável ao ambiente externo, o que acirra as condições de desconforto ambiental para o frio. Todavia, a maior evidencia dos extremos térmicos e da formação de desconforto ambiental nas áreas urbanas brasileiras está relacionada ao excesso de calor (médias diárias e sazonais superiores a $30^{\circ} \mathrm{C}$ e $25^{\circ} \mathrm{C}$, respectivamente) em toda a porção central, sudeste, norte e nordeste do país. As ilhas de calor urbanas atingem níveis consideráveis (acima de $12^{\circ} \mathrm{C}$ de magnitude nas cidades médias e grandes), mas conjugam-se com a formação de ilhas de frescor, particularmente nas regiões agrícolas cujo rítmico de colheitas evidencia características urbanas de ilhas verdes de vegetação nos momentos de entressafras anuais (MONTEIRO; MENDONÇA, 2003).

Situações de risco ao desconforto térmico e à formação de ilhas de calor intensas podem ser observadas como condições naturais em todas as cidades brasileiras, mas a vulnerabilidade social à estes eventos é bastante seletiva; ou seja, as repercussões sobre o desconforto térmico se fazem notar especialmente sobre a população pobre, uma vez que ela não possui as condições econômicas, técnicas e científicas para fazer face à influencia do clima sobre suas vidas. Na organização do espaço urbano brasileiro observa-se, facilmente, os resultados benéficos do planejamento urbano à uma pequena parcela da população (classe alta e dirigentes) em cujos bairros o urbanismo permitiu a formação do efeito-parque/efeito-lago como dinamizadores do clima urbano e, portanto, com extremos térmicos menos evidentes. O paradoxo dessa forma de produção do espaço revela-se também no mais elevado nível de formação escolar, na melhor condição econômica, técnica e política da população que nestas áreas habita.

Da mesma forma observa-se as mesmas condições de riscos naturais no que concerne ao subsistema hidrometeórico pois, nas cidades brasileiras, especialmente naquelas situadas na fachada leste do país, os episódios sazonais (verão prolongado) de inundações associadas, em boa parte das vezes, a deslizamentos de terra são flagrantes. O numero de vítimas fatais, o montante de perdas econômicas e as complicações de saúde derivados destes processos explicitam, de maneira mais evidente que o desconforto térmico, a alta vulnerabilidade social da população urbana brasileira aos episódios de chuvas concentradas ou prolongadas, mesmo que com totais baixos diários.

Episódios como os registrados nas últimas décadas nas cidades do Rio de Janeiro (e cidades da Região Serrana, fortemente abaladas pelos impactos das chuvas concentradas em 2011/2011), Belo Horizonte, Salvador, Florianópolis, Itajaí/Blumenau, litoral do Paraná (2011) e muitas outras são reveladores da completa dissonância entre a ação do poder público e a dinâmica social na ocupação dos espaços. Se por um lado faltam políticas e investimentos sólidos no ordenamento e ocupação do solo urbano, por outro o descompromisso e desatenção (desconhecimento dos riscos?) para com a ocupação das áreas de risco por parte da população torna os impactos ainda mais graves

A responsabilidade pelos problemas é de ambas as partes, ainda que sobre uma delas - a população pobre - a injustiça social tenha gerado entraves profundos quanto à tomada de consciência e envolvimento nos processos de transformação social e de suas próprias vidas.

No que concerne à poluição do ar urbano - susbsistema físico-químico - ele constitui o campo de menor enfoque nos estudos dos climas do Brasil. Este fato não implica, necessariamente, na compreensão de que as cidades brasileiras não são poluídas, mas decorre do alto custo dos equipamentos para aferir a qualidade da atmosfera urbana. Assim, somente cidades grandes e industrializadas 
como São Paulo, Rio de Janeiro, Belo Horizonte e Curitiba, dentre algumas outras, contam com investigações acerca da contaminação da atmosfera urbana, da formação de situações de inversão atmosférica e da ocorrência de chuvas ácidas no tecido urbano.

Com a expansão da produção canavieira no país, decorrente das políticas de produção de bioenergia e no âmbito da qual o uso do álcool combustível é concebido como uma saída para a grave crise ambiental e energética do mundo atual, a poluição atmosférica de muitas regiões no interior do país se intensificou de forma assustadora. A queima da cana e o processo de produção do álcool lançam quantidades elevadíssimas de fumaça, particulados, gases e calor na atmosfera, fato que turva e contamina o ar das cidades localizadas nestas regiões, o que demanda maiores investimentos da ciência geográfica na compreensão dos problemas socioambienais destas áreas urbanas.

\section{CONSIDERAÇÕES FINAIS}

Três são as formas de manifestação dos riscos, a natural, a tecnológica e a social; cada uma delas pode se manifestar de maneira isolada, todavia, a associação de duas ou mais formas caracteriza boa parte dos processos nos quais a sociedade humana é colocada em perigo. Os riscos socioambientais podem se manifestar para toda a população de uma determinada área num certo momento, especialmente quando da ocorrência de hazards (naturais, sociais e tecnológicos), mas não atinge a todos da mesma maneira. Este último aspecto coloca em evidencia as diferentes formas de suscetibilidade das populações aos impactos dos eventos extremos, sendo neste caso evidenciada a vulnerabilidade socioambiental das populações aos riscos socioambientais.

Enquanto a formação de situações de excepcionalidade climática revela, particularmente, uma condição natural dos riscos, as diferenciações socais, políticas, econômicas e culturais das populações revelam, por seu lado, condições de injustiça social que se ligam, diretamente, às diferenciações da vulnerabilidade socioambiental das populações aos eventos extremos.

Muito recentemente nota-se o inicio do emprego da concepção de resiliencia à analise das manifestações de fenômenos de caráter extremo; todavia, parece ser necessário uma melhor discussão e aprofundamento desta perspectiva, pois o retorno às condições pré-acidentes da grande parte das populações dos países não desenvolvidos é lastimável para se desejar voltar a ela.

O emprego destas três concepções na ciência em geral, e na geografia em particular, tem provocado importantes transformações na forma de conceber e analisar o espaço geográfico. A mais importante delas talvez seja a mudança do enfoque, ou seja, as três perspectivas irrompem com a leitura "estática" do espaço e colocam sua dinâmica em evidencia; elas impõem a necessária abordagem da condição passada de uma dada realidade espacial em apreço, forma direta de conceber o presente como seu resultado, mas inserem o exercício da construção da situação (cenário) futura. Desta forma o planejamento urbano e regional, por exemplo, conduzem a atuação do geógrafo a não mais realizar projeções sobre um espaço imóvel, mas sim, a considerá-lo sob um ponto de vista de intenso dinamismo; obriga-o, de certa maneira, a exercitar um pouco mais sua criatividade científico-técnica.

O estudo do clima urbano registra avanços consideráveis no presente, sendo este um campo especial de estudos da climatologia. Destaca-se, no âmbito brasileiro a proposta do SCU - Sistema Clima Urbano, fartamente aplicada em estudos no país, e reapropriada mais recentemente com a proposta de analise do SAU - Sistema Socioambiental Urbano. Ambas tomam o estudo do clima e do ambiente da cidade a partir de uma perspectiva integradora dos elementos naturais, sociais e construídos da cidade; nesta perspectiva observa-se um considerável avanço na analise dos problemas socioambientais urbanos.

Mais recentemente, com a intensificação do processo de urbanização e sua tendência em agudizar-se na forma de cidades-região gigantescas nas próximas décadas, especialmente na América Latina, África e Ásia, o estudo do clima urbano e dos problemas socioambientais a ele relaciona- 
dos toma maior vigor. Assim, o desconforto térmico, as inundações e a poluição do ar constituem problemas de expressivo interesse da climatologia e dos geógrafos na atualidade, associados aos quais a analise dos riscos e vulnerabilidades socioambientais urbanos traz importantes contribuições à gestão da cidade. Particularmente no âmbito das discussões relativas às mudanças climáticas globais, é preciso enfatizar, e ainda que a temática esteja fortemente revestida de controvérsias, há que se considerar que a formação de riscos e vulnerabilidades socioambientais ao clima deva se intensificar; isto decorre não somente de mudanças ou variabilidade nos climas do planeta, mas sobretudo à expansão das áreas urbanas no presente e a perspectiva futura para o desenvolvimento das mesmas.

\section{REFERENCIAS BIBLIOGRÁFICAS}

BACHELARD, Gaston. A formação do espírito científico: contribuição para uma psicanálise do conhecimento. Rio de Janeiro: Contraponto 1996.

BECK, Ulrich. La sociedad del riesgo. Hacia una nueva modernidad. Madrid: Paidos, 1998. DUBOIS-MAURY, J. et CHALINE, C. Les risques urbains. Paris: Armand Colin, 2002.

KUHN, Thomas S. A estrutura das revoluções científicas. São Paulo: Perspectiva, 2007.

MENDONÇA, Francisco. Impactos sociombientais urbanos. Curitiba: Editora da UFPR, 2004.

MENDONÇA, Francisco. Riscos, vulnerabilidade e abordagem socioambiental urbana: Uma reflexão a partir da RMC e de Curitiba. Desenvolvimento e Meio Ambiente, n. 10, jul./dez. 2004a. p. 139-148.

MENDONÇA, Francisco. Geografia, geografía física e meio ambiente: Uma reflexão à partir da problemática socioambiental urbana. Revista da ANPEGE, v. 5, 2009. p. 174-189.

MONTEIRO, Carlos A. F.; MENDONÇA, Francisco. Clima Urbano. São Paulo: Contexto, 2003.

OKE, Timoty. Boundary layer climates. New York: John Wiley \& Sons, 2a Edição, 1987.

SANTOS, Milton. A urbanização brasileira. São Paulo: Hucitec, 1993.

SERRES, Michel. Le contrat naturel. Paris: Flamarion, 1993.

VEYRET, Yvete. Os riscos. São Paulo: Contexto, 2007.

Trabalho enviado em agosto de 2011

Trabalho aceito em outubro de 2011 